\title{
The Effect of Using Computer Program on Developing Verbal Communication among Mentally Retarded Children in the Elementary Stage in Rafha Province
}

\author{
Essam Abdou Ahmed Saleh ${ }^{1}$, Khaled Ahmed Mahmoud Attia ${ }^{1}$ \& Alaa Ahmed Hassan Al-Jundi ${ }^{1}$ \\ ${ }^{1}$ Department of Education, Faculty of Science and Arts, Northern Border University, Rafha, KSA \\ Correspondence: Essam Abdou Ahmed Saleh, Department of Education, Faculty of Science and Arts, Northern \\ Border University, Rafha, KSA. E-mail: dresam1969@yahoo.com
}

Received: January 31, 2017 Accepted: February 16, 2017 Online Published: March 1, 2017

doi:10.5539/ijel.v7n3p171 URL: http://doi.org/10.5539/ijel.v7n3p171

\begin{abstract}
This study aims at investigating the effect of using a computer program on developing verbal communication among the educable mentally retarded students in the elementary stage in Rafha Province. The sample was selected from the students of the intellectual education classes in the elementary stage in Rafha province/ Northern Borders Region. The researchers followed the experimental method to conduct the study. The sample consisted of 20 students randomly distributed into two groups: an experimental group that was taught using the suggested verbal communication developing computer program and a control group that did not receive any educational program. The program was made up of 21 sessions. Each session lasted for 45 minutes, three times a week. The researchers used verbal communication scale to collect data and to compare the performance of the experimental and control groups in the pre and post tests. The results of the study indicated that there are statistically significant differences on the verbal communication scale among the students of the two groups at the level of (0.01) in favor of the experimental group.
\end{abstract}

Keywords: computer program, verbal communication, mentally retarded

\section{Introduction}

Computer is considered as an important tool in the life of the special needs people in general and those with mental retardation in particular. Acquiring the verbal communication skills is also an important matter that increases the special needs efficiency in dealing with life aspects and enhances their interaction with life; consequently, they can greatly achieve their personal independence in life.

In our current time, education is no longer interested in those with high or moderate level of mental abilities, on the contrary, the educational efforts are targeting all the youth despite their mental levels or comprehension abilities.

The interest in using computer has increased during the last decades. It played a crucial role in teaching both the normal and retarded students (Ray \& Warden, 1995).

Computer has the ability to help students with mild mental retardation to overcome many obstacles that hinder their independence and achievement in school. Those students, who use computers, were able to communicate with others, participate in the social and educational activities, work and be independent in the daily life skills (Copel, 1991).

The verbal communication is considered as one of the most important communication skills because the sender is trying to deliver the maximum amount of the message's meaning by pronouncing words. Verbal communication includes words pronunciation, which is defined as "air waves which are mostly produced in the throat and formed by the sounds organs" (Al-Mu'jamul Waseet, 2004).

Sieler \& Beall (2005) indicate that language is one of the communication elements, but the existence of the language alone does not necessarily means the existence of communication. In any language writing and speaking are different skills. The primary objective of learning a language is to grant the learner the ability to verbally communicate in a clear and appropriate way whether this communication is written or verbal. This objective can be obtained through the four communication skills: listening, speaking, reading and writing, which 
are the bases of the linguistic connection. Language is an integrated entity in which any skill is affected by the other skills. For this reason, the curricula of these skills must not be considered as an end by itself, but as a medium that leads to that end. This end is adjusting the students' linguistic behavior through their interaction with the linguistic activities and experiences in the curriculum.

Shehata (2003) confirms that the lack of concept and symbolic function hinders the language acquisition among mentally retarded. The deficiency is in the concept itself. The mentally retarded child shows serious tardiness in the sensory development. The mentally retarded child always has a hard beginning with language. He starts pronouncing some words clearly at early stages then he seems to forget these words and stop pronouncing them again for some months. He usually does not speak between the age of 2 and 3 and may not speak at all. The mentally retarded child also suffers from the delay of being able to imitate adults in the terms of language and behavior, in addition to that there is also the delay of being able to express himself and understand words, so; he seems to be unable to understand and rarely pay attention to what is said to him due to his weak ability to concentrate.

Rosan (2001) clarifies that language acquisition is possible for this category, but the language remains incomplete since it lacks the words and the grammar. Sometimes the mentally retarded child gives the people surrounding him the false impression that he uses correct sentences, but in fact he does not understand what he says. Which means that he may repeat such sentences after hearing them from an adult the same way a parrot does. Hence, the main problem is the delay of acquiring language and using it as a mean of expression and communication.

Most of the contemporary educational trends call to take care of the child's language growth and the methods and programs that develop his language, so the interest has increased in the computer assisted learning that uses the developed interactive techniques such as the multimedia and the virtual reality.

The importance of using computer has increased in the last decades. It plays a significant role in teaching both the normal and retarded students (Ray \& Warden, 1995). Computer has the ability to assist students with mild mental retardation to overcome many obstacles that prohibit their independence and education.

\subsection{Problem Statement}

Using computer has a great importance in the educational process for all the students including the students with special needs. The category of students with mild mental retardation is one of the special education categories. This category needs this technical device to acquire the verbal communication skills due to the fact that it is one of the interesting educational aids based on the individual learning, which is the kind of learning called for by the modern education of the students with special needs.

Many studies related to children with mental retardation proved that using computer has positive effect on improving language skills. It also proved that students who use computer achieved higher marks than the students who follow the traditional methods of learning (Stromer et al., 1996; Yeuingoo Lee, 2001; Heimann et al., 2001; Mechling, Gast, \& Langone, 2002; Aweys, 2007).

The problem of the study clarifies the need of a computer program which is based on proposed activities that comply with the nature and characteristics of the mentally retarded children. We seek to develop the verbal communication among the mentally retarded students through the students' interaction and their practice of these activities.

The current study, with its educational program that uses computer, aims to develop verbal communication among the educable mentally retarded students. In the light of the foregoing, the current study answers the following question:

\section{Is there an effect for using a computer program on developing the verbal communication among educable mentally retarded students?}

\subsection{The Purpose of the Study}

The purpose of this study is to investigate the effect of using computer program on developing verbal communication among mentally retarded children in the elementary stage.

\subsection{The Significance of the Study}

This study will contribute to the clarification of the importance of using computer in developing verbal communication among mentally retarded children because it plays a great role in developing their skills. Computer has significant capability regarding accuracy, speed and control of the educational material. The significance of this study lies in the following points: 
- Approaching a very important element of the educational process which is using computer.

- Tackling an important part of the educational process which is the development of verbal communication among mentally retarded students.

- Drawing attention to the role of computers in preparing the mentally retarded students to face the challenges of life.

- Trying to develop the verbal communication among educable mentally retarded students.

- Developing an educational computer program and investigating its effect in developing the verbal communication among educable mentally retarded students.

- Providing a tool to evaluate the verbal communication among educable mentally retarded students.

\subsection{The Study Terminology}

- The Computer Program: It is the techniques, strategies, tools and methods which are used to develop verbal communication among educable mentally retarded students by using computer programs.

- Verbal Communication: It is the translation of the ideas into specific words and arranging these words in a way that enables the individual to render his message either through speaking or writing (Albiblawi, 2006, p. 24). The researchers define it as a system of learning and teaching activities that leads to communication between the students (the study sample). It seeks to communicate information since it is an uninterrupted continues activity that cannot be repeated, deleted or reversed.

- The Educable Mentally Retarded Children: They are the children whose IQ ranges from 55-75. They can be taught some of the academic, linguistic and social skills. They can also take advantage of some regular educational programs but they make a slow progress in comparison with the regular children.

\subsection{The Study Limitations}

This study is limited to the mentally retarded students in the elementary stage of the intellectual schools in Rafha Province. The students are 8 to 11 years old.

\subsection{The Study Variables}

The current study consists of the following variables:

- $\quad$ The independent variable: the cognitive behavioral computer program concerning some lexical items.

- The dependent variable: verbal communication.

\subsection{The Theoretical Framework}

The researchers try through the theoretical framework to shed light on the study elements that correlate to using computer in developing the verbal communication skills among the mentally retarded students as follows:

\section{Mental Retardation:}

Mental retardation has several definitions that reflect the developments related to the concept as a result of the developments in the society in general and in the society of retarded persons in particular. By reviewing the definitions, we find out that these definitions vary according to the various points of view of mental retardation. Some consider it a social problem; others look at it as a medical problem while others consider it an educational problem.

The American Psychiatric Association (A.P.A, 1994) defined mental retardation in the DSM-IV catalogue of mental disorders as a significantly sub average intellectual functioning with an IQ of approximately 70 or below, tested individually, and in the case of children there must be a clinical report indicates the existence of a sub average intellectual functioning.

Due to the fact that the current study is interested in the educational aspect, the researchers define the retarded child as "the child who is unable to obtain the normal academic achievement level of his normal fellow students and has an IQ of 50-70, so this category is considered as the category of educable students".

\section{Linguistic Features of Educable Mentally Retarded Students:}

Farouk Rosan (2001) indicated that many studies confirmed that there are differences between the normal and retarded students in regard of the level and average of language growth. He stated that the most common language problems among mentally retarded students are; pronunciation problems, stuttering, lack of lexical items and weakness of grammatical structures. The language problems are more common among the retarded student than among the normal ones. Also, some studies showed that there is a correlation between the degrees 
of mental retardation and the aspects of language disorders. Accordingly, children with mild mental retardation may have a speech delay but they rarely suffer from Muteness.

\section{Verbal Communication:}

Communication is considered as an essential part of our life. All types of communication, whether oral, written or non-verbal, make the largest part of what we daily do since we spend $50-75 \%$ of day time in communication. Effective communication is considered a skill that can be developed through training and practice. Through communication we equally develop our understanding to ourselves and others (Taima, 2006).

Qasim (2000) indicated that communication is a process of production and exchange of data, thoughts, opinions and feelings between one person and another in order to have an influence and obtain a reaction. There are two types of communication:

- Verbal communication that includes two skills; speaking and listening.

- Written communication that includes two skills; writing and reading.

\section{The Effects of Computer on the Education of the Mentally Retarded Children:}

Julie \& Lawrence (1996) indicated that computer plays a significant role in teaching the retarded. It is considered an effective way to ease the burden of teaching the retarded children. Computer can also improve the basic cognitive processes; attention, perception and remembering. It reduces the time spent by students in the direct study of the academic subjects. Therefore; computer has the ability to provide an individual practice more stimulating than the one provided by the traditional teaching methods.

Lerner (2000) indicated that computer provides the students with instant feedback; it also goes from the simple directions to the longer and more complicated ones. These programs dialogue with the student constantly (for example: try again, are you sure, would you like to change your answer). Such programs vary from practice and repetition programs to problem solving programs.

Smith (1988) clarified that using computer in teaching reading to the students with mild mental retardation has an ultimate importance and benefit. The computer can develop their comprehension for a large group of reading skills including the movement of eyes on the lines and following the reading methods appropriately.

The problem of his study lies in the weakness verbal communications among the mentally retarded students as a result of their intellectual characteristics, abilities and needs, which necessitates developing the language of this category. This development can be achieved by developing some of the reading and writing skills, which is the most effective verbal communication method and considered as a must in the case of mental retardation.

It is noticed that the mentally retarded students suffer from many problems such as the decrease of the linguistic and pronunciation characteristics.

\subsection{Literature Review}

Scott Baker et al. (1995) conducted a study that aims at studying the language growth and its effectiveness on number of learners. This study is considered as one of the modern studies in language growth. The results of the study showed that the number of lexical items vary from one learner to another, since there are some factors that contribute in determining the individual differences regarding the acquisition of lexical items. These factors include; vocabulary, memory weakness and the educational plan for language acquisition training. It was found that there are successful ways to enhance language among the special needs students.

Stromer et al. (1996) conducted a study to know the extent of the effectiveness of computer teaching programs in training the mentally retarded to learn the alphabet. The results showed that using the sets method in learning the alphabet may achieve functional results using multimedia, but the reviewing attempts after the training indicated low performance when applied without using the set.

Yeuingoo Lee (2001) sought in his study to reveal the effect of multimedia in teaching children with mentally retardation how to differentiate between the words. The results of the study indicated that four of the sample members learnt the positions of the word using the computer program. While one of the sample members was not affected by the program. The sample's members acquired secondary information, which was gained through the programs events, the used models, the tools and facilities.

In their study, Heimann et al. (2001) aimed at investigating the interaction between the autistic and mentally retarded children on the one hand and their teachers on the other when using a developed multimedia that seek to improve the reading and writing skills among those children. The results of the study showed that all the sample members demonstrated an obvious improvement in their lexical expression after using the program. 
Mechling et al. (2002) conducted a study to evaluate the effectiveness of using computer based video instructions to teach students with mentally retardation the skill of reading grocery aisle signs in order to locate the items and link them to their name. The study used different daily life educational examples. The results of the study revealed that the computer based video instructions enhanced the students' performance and enabled them to read and understand words. Using photos and linking them to written words helped the students with moderate mentally retardation in recognizing words and linking them to their items.

Kashif (2002) also conducted a study using a computer based program to develop some language skills among educable mentally retarded students. The results confirmed the effectiveness of using computer in developing the experimental group's language skills in comparison with the control group.

Faraj (2003) aimed at developing some language skills among educable mentally retarded students through using computer programs. The results asserted the effectiveness of using computer in developing the language skills of the experimental group, which received training, in comparison with the control group. That confirmed the effectiveness and benefits of using computer based language training programs to teach the mentally retarded students.

The aim of Aweys's study (2007) was to determine the effectiveness of a training program based on the early intervention in enhancing the social and linguistic skills among a sample of children with mental retardation. The results showed that there are statistically significant differences on the social and linguistic skills in the post test in favor of the experimental group.

Hlipe (2008) conducted a study to recognize the effectiveness of a computer program on developing the vocabulary of the educable mentally retarded students. The results indicated that the program had a positive impact on the development of functional vocabulary.

Moussa (2009) investigated the impact of a training program in the Arabic language on the development of some of the functional linguistic expression skills among the educable mentally retarded students. The study showed the superiority of the group that was taught using the program, since there were statistically significant differences between the pre-test and post test in favor of the post test.

\section{A Comment on the Previous Studies:}

- All the studies, related to the mentally retarded students, revealed the effectiveness of the programs and activities on the enhancement of the language and showed that the students who use computer achieve marks higher than the marks of those who learn using the traditional ways. The following are some of these studies: Stromer et al., 1996; Yeuingoo Lee, 2001; Mechling, Gast, Heimann et al., 2001; Langone, 2002; Aweys, 2007.

- Most of the studies showed the effectiveness of using computer in developing the language skills among the students with mental retardation. Such as Faraj, 2003; Hlipe, 2008; Moussa, 2009.

- The educable mentally retarded students in the elementary stage suffer from severe lack of language skills and verbal communication.

\subsection{Study Hypotheses}

- There are no significant differences at the level of $(0.01)$ on the verbal communication between the means of the two groups in the post tests on the overall grade of the verbal communication scale.

- There are no significant differences at the level of $(0.01)$ on the verbal communication between the means of the pre- and post tests of the experimental group in regard of the verbal communication.

- There are no significant differences at the level of $(0.01)$ on the verbal communication between the means of the post test and the follow-up test in regard of the verbal communication scale.

\section{Method}

\subsection{Sample of the Study}

The sample consisted of 20 students studying in some intellectual classes in the elementary stage in Rafha Province. The sample was divided equally into experimental and control groups each group consisted of 10 students. Both groups were equal in terms of age (8-11 years old), gender and class level. The sample was picked intentionally from the educable mentally retarded classes in Haroun Alrashied elementary school in the academic year 2014-2015.

\subsection{The Research Instruments}

The Verbal Communication Scale (designed by the researchers): 
For the purposes of the current study, a verbal communication scale was used. It was taken into consideration that the language of the phrases used in this study was simple, clear and short. The scale consisted of 15 items convenient to the students with mild mental retardation from the age of 8 to 11 . The scale was designed to be applied upon the child himself without relying on the points of view of his teacher, father or mother.

The Scales Validity: The researchers measured the scale's validity by consulting eight arbitrators (the eight arbitrators are university professors who are specialist in the field of special education). The arbitrators agreed unanimously, with rates ranged from $92 \%-96 \%$, on the adequacy of the scale's item. Thus, the scale's validity was approved after making the modifications required by some arbitrators.

The Test Reliability: The researchers measured the reliability of the test by applying it on the standardization sample with a time lag of 15 days. The correlation between the two tests was (0.842), which indicates the reliability of the test.

The Training Program: (designed by the researchers):

The following is a description of the steps and procedures followed by the researchers to reach the main objective of the study, which is creating a computer based training program to develop the verbal communication among a sample of educable mentally retarded students in the elementary stage of the intellectual schools.

The Steps of Creating the Program: the researchers prepared the program using computer. They created the primary formulation of the program then consulted a committee of specialists and experts. The committee's opinion was taken into consideration to determine the program's validity and adequacy in developing verbal communication among the students of the elementary stage in the intellectual schools (the educable mentally retarded students). The specialists and experts committee was formed from a number of staff members in Northern Borders University.

The Program's Content: The program was made up of 21 sessions. Each session lasted for 45 minutes, three times a week. During the session the following took place:

- Making the children acquainted with; the researcher, each other and the computer that will be used during the training.

- Allowing the children to acquire familiarity with the lexical items and activities they are exposed to and distinguish between them.

- Making the children positively engaged in the sessions' events and activities.

Table 1. The following is a table of the subjects in the program's 21 sessions

\begin{tabular}{|c|c|c|c|}
\hline $\begin{array}{l}\text { Session } \\
\text { Number }\end{array}$ & Subject & $\begin{array}{l}\text { Session } \\
\text { Number }\end{array}$ & Subject \\
\hline 1 & Body parts and their functions & 12 & Geometric shapes \\
\hline 2 & Home furniture & 13 & Fruits and vegetables \\
\hline 3 & Schools facilities & 14 & Different occasions \\
\hline 4 & Things in the street & 15 & Antonyms (big/ small), (short/ tall), (hot/cold), (fat/ thin) \\
\hline 5 & Jobs (teacher, doctor, engineer, carpenter, etc.) & 16 & $\begin{array}{l}\text { Using verbs such as the child reads, laughs, is happy, is } \\
\operatorname{sad...}\end{array}$ \\
\hline 6 & Foods and drinks & 17 & Speaking and communicating with others \\
\hline 7 & Animals and their sounds & 18 & Following directions \\
\hline 8 & $\begin{array}{l}\text { Colors and their relation to the usages and things } \\
\text { in life }\end{array}$ & 19 & Behaving with others \\
\hline 9 & Transportations and their sounds & 20 & Time concepts like; yesterday, today, night, day... \\
\hline 10 & Clothes of different seasons & & Spatial concepts such as; (up/ down), (in the middle/ at \\
\hline 11 & $\begin{array}{l}\text { Daily activities such as; knocking the door, } \\
\text { brushing teeth, studying... }\end{array}$ & 21 & the end), (right/ left) \\
\hline
\end{tabular}

\section{The Strategies Used in the Study:}

- Individual teaching: each student is allowed to work individually according to his ability using a computer for each child.

- Drawing attention: the child focuses his senses and mind on consecutive stimuli during the period of training. 
- The researcher used tangible and intangible reinforcements to stimulate the desirable response.

- Feedback: the students received information about their performance.

\subsection{Research Procedure}

After constructing the training program and finalizing the study tools, the study was carried out following these steps;

- Locating the elementary stage schools which have intellectual classes for the educable mentally retarded students aged 8 to 11 years.

- Formally identify the educable students with mild mentally retardation using scientific approach and special tests to diagnose the cases of mild retardation.

- Intentionally picking the sample.

- Randomly distribute the students into two groups; experimental and control groups.

- Before conducting the study, the two groups submitted to a pre-test which applies the study tool (verbal communication scale).

- The researchers carried out 21 sessions. Each session lasted for 45 minutes, three times a week.

- Immediately after the end of the study, the two groups submitted to a post-test which reapplies the study tool (verbal communication scale).

- The data were statistically processing to check the study hypotheses.

\subsection{The Study Design}

The current study is an experimental study that has two variables: dependent and independent. The control and experimental groups were pre and post-tested as the follows:

Experimental group: Random choice- pre test- processing- post test.

Control group: Random choice- pre test- without processing- post test.

Table 2. The study design table

\begin{tabular}{llll}
\hline Group & pre test & Processing & post test \\
\hline Experimental & verbal communication & Applying the training program & verbal communication \\
Control & verbal communication & without processing & verbal communication \\
\hline
\end{tabular}

\subsection{Statistical Processing}

To answer the study questions and to check its hypotheses, a statistical processing of data was conducted using the Wilcoxon Test.

\section{Results}

\subsection{Results Related to the First Hypothesis}

To check the first hypothesis, which states that "there are no significant differences in verbal communication between the experimental and control groups in the post test regarding the overall grade of the verbal communication test".

To validate this hypothesis, the difference between the means of the students' grades in both the experimental and control groups was calculated using the Mann-Whitney test. Table 3 illustrates the results which the researchers conclude on the verbal communication scale.

Table 3. Illustrates the significance of the differences between the grades' ranks of the students of the experimental and control groups in the post test on the verbal communication scale

\begin{tabular}{llllll}
\hline Group & $\mathrm{N}$ & Mean Rank & Sum of Ranks & Z Value & Significance level \\
\hline Control & 10 & 5.50 & 55 & 3.79 & 0.01 \\
Experimental & 10 & 15.50 & 155 & & \\
\hline
\end{tabular}


Table 3 clarifies that there are statistically significant differences between the post tests' means of the students of the experimental and control groups on the verbal communication scale in favor of the experimental group since the $(\mathrm{Z})$ value is significant at the level of $(0.01)$ which indicates the effectiveness of the proposed educational program.

\subsection{Results Related to the Second Hypothesis}

To check the second hypothesis, which states the following; "there are no significant differences on the verbal communication between the means of the pre- and post tests of the experimental group on the verbal communication scale".

To check this hypothesis, the difference between the means of the experimental group students' grades in the preand post tests was calculated using the Wilcoxon test. Table 4 represents the results reached by the researchers on the verbal communication scale.

Table 4. Illustrates the significance of the differences between the means of the experimental group students' grades in the pre- and post tests on the verbal communication scale

\begin{tabular}{llllll}
\hline & $\mathrm{N}$ & Mean Rank & T Value & Z Value & Significance level \\
\hline Negative Ranks & 6 & - & & & \\
Positive Ranks & 4 & 5.50 & 55 & 2.812 & 0.01 \\
Ties & 0 & - & & & \\
\hline
\end{tabular}

Table 4 shows that there are statistically significant differences on the verbal communication scale between the means of the experimental group students' grades in the pre- and post tests in favor of the post test, since ( $\mathrm{Z}$ ) value is significant at the level of (0.01) which indicates the effectiveness of the program in developing the verbal communication.

\subsection{Results Related to the Third Hypothesis}

To check the validity of the third hypothesis, that states: "there are no significant differences between the means of the post test and the follow-up test of the experimental group on the verbal communication scale".

To check this hypothesis, the difference between the means of the experimental group students' grades in the post test and the follow-up test was calculated using the Wilcoxon test. Table 5 illustrates what the researchers found on the verbal communication scale.

Table 5. Clarifies the significance of the differences between the means of the experimental group students' grades in the post and the follow-up tests on the verbal communication scale

\begin{tabular}{llllll}
\hline & N & Mean Rank & T Value & Z Value & Significance level \\
\hline Negative Ranks & 6 & 6.5 & & & \\
Positive Ranks & 4 & 4 & \multirow{2}{*}{16} & 1.173 & Insignificant \\
Ties & 0 & - & & \\
\hline
\end{tabular}

Table 5 clarifies that there are no statistically significant differences on the verbal communication scale between the means of the experimental group students' grades in the post and follow- up tests, since (z) value is insignificant, which also indicates the effectiveness of the new computer program .

\section{Discussion}

The results of the study indicated the effectiveness of using the computer program, which has a notable clear effect on improving the level of verbal communication among the members of the experimental group in comparison with the control group. The following is a detailed discussion of the results related to the study hypotheses;

\section{Firstly: Discussing of the results related to the first hypothesis:}

The results related to the first hypothesis, which states that "there are no significant differences at the level of (0.01) in verbal communication between the experimental and control groups in the post test regarding the overall grade of the verbal communication test" indicated that the experimental group, which learnt using the computer program, demonstrated the effect of the program in developing the verbal communication. That was clear due to the existence of significant differences between the experimental and control groups in the post test. 
The results of this study conformed to the results of Stromer et al. (1996) which showed the effectiveness of using the sets method in learning the alphabet. This method achieved functional results using multimedia, but the reviewing attempts after the training indicated low performance when it was applied without using the set. The results of the current study also agreed with the study of Yeuingoo Lee (2001) which indicated that four of the sample members learnt the location of the word using the computer program. The sample's members also acquired secondary information such as the definition of the word. The information was gained through the programs events; the used models, the tools and the facilities. The current study came in accordance with the study of Mechling et al. (2002) that indicated the effectiveness of using computer based video instructions to teach students. This method increased the students' ability in reading and understanding words. Using photos and linking them to written words helped the students with moderate mentally retardation to recognize words and link them to their items. This study also agreed with Faraj's (2003) study that showed the effectiveness of using computer in developing the language skills of the experimental group that received training, in comparison with the control group. Finally the current study conformed to the study of Hlipe (2008) which results indicated that the computer program had a positive impact on the development of functional vocabulary.

\section{Secondly: Discussing of the results related to the second hypothesis:}

The results related to the second hypothesis, which states the following; "there are no significant differences at the level of (0.01) on the verbal communication between the means of the pre- and post tests of the experimental group on the verbal communication scale", showed that there are statistically significant differences on the verbal communication scale between the means of the experimental group students' grades in the pre- and post tests in favor of the post test, since $\mathrm{z}$ value is significant at the level of $(0.01)$ which indicates the effectiveness of the computer program. This is generally agreed with many previous studies that indicated the effectiveness of using a computer program in developing the verbal communication among the mentally retarded students. The result of the current study conforms to the results of Stromer et al. (1996), Yeuingoo Lee (2001), Heimann et al. (2001), Mechling et al. (2002), Faraj (2003) and Hlipe (2008). The results of these studies indicated the effectiveness of using computer program in training the mentally retarded students to learn the alphabet and that the computer program helped them to learn the word's location and to demonstrate a clear improvement in the verbal communication using the computer program. The studies also revealed that using the computer based video instructions to teach students enhanced their performance and allowed them to read and understand words. The results also mentioned that using photos and linking them to written words helped the students with moderate mentally retardation in recognizing words and linking them to their items. These results indicated the effectiveness of using computer in developing the language skills of the experimental group, which received training, in comparison with the control group.

\section{Thirdly: Discussing of the results related to the third hypothesis:}

The results related to the third hypothesis, which states that: "there are no significant differences between the means of the post test and the follow-up test of the experimental group on the verbal communication scale", indicated that there are no statistically significant differences on the verbal communication scale between the means of the experimental group in the post and follow- up tests, since $\mathrm{z}$ value is insignificant, which indicates the effectiveness of the new computer program.

The results indicated that the computer based training program has an effect on developing the verbal communication among a sample of educable mentally retarded students which clarifies and confirms the importance of the training program used in this study in developing the verbal communication of the experimental sample.

The reason behind these positive results could be related to the nature of the program and the way its components and activities are linked to each other. The training program tackles many concepts and daily life lexical items obtained from the student's social life. The program increased the students' ability to verbally communicate during the sessions that contributed to the stimulation process.

The fact that the program discussed many concepts and lexical items provides the students with accumulative knowledge that contributes in developing their verbal communication.

The way of carrying out the program may be another factor related to the positive results of the study. The training sessions took place in a safe psychological atmosphere. The individual teaching strategies were followed and the utmost attention was paid to the students. The tangible and intangible reinforcements were used and the students received feedback. All these factors helped the students to develop their Self-confidence and gave them the chance to give their best performance. 


\section{Conclusion}

In light of the study results and conclusions and after discussing the results, the researchers recommend the following:

- The necessity of using computer programs in developing the verbal communication. Using these programs is one of the effective teaching methods that lead to achieve many objectives especially with the mentally retarded students.

- The necessity of using this program by educational counselors and the special education teachers, in addition to distributing it to the schools interested in the educable mentally retarded students.

- The necessity of paying more attention by technology centers to design the mentally retarded educational programs that can be used in curricula, especially the curricula of teaching the mentally retarded students.

\section{Acknowledgments}

Essam Abdou Ahmed Saleh, Khaled Ahmed Mahmoud Attia and Alaa Ahmed Hassan Al-Jundi are supported with the research grant No (435-072-8) Deanship of Scientific Research, Northern Border University, Arar, KSA.

\section{References}

Arabic Language Academy. (2004). Lexicon Intermediate. Cairo library Sunrise International.

Aweys, Y. (2007). Vaalah based on early intervention to improve the social and language skills among a sample of children with mental disabilities in early intervention centers in the city of Damascus software training program. Master-Damascus University.

Copel, H. (1991). Tech use guide: students with moderate cognitive abilities (Technical Report). Reston, VA: Center for Special Education Technology.

Faraj, I. M. S. (2003). Some linguistic skills development category mentally handicapped children who are able to learn to use computer programs. Master Thesis, Ain Shams University.

Fouad, I. (2002). The effectiveness of computer programs to improve learning some skills for children with mental disabilities. Egyptian Journal of Psychological Studies -aladd, 35(XII), S102-143 -alcild.

Heiman, M. T. J., \& Nelson, K. E. (2001). Interaction patterns between children and their teachers when using a pacific multimedia and communication strategy: observation from children with autism.

Hlipe, M. M. (2008). A software program for the development of functional vocabulary among students with mental disabilities who are able to learn in first grade schools arranged for Intellectual Education. Scientific Conference twenty - education and cultural identity curricula, Egypt, 3, 874-925.

Julie, M., \& Lawrence, L. (1996). Bimodal reading: benefits of a taking computer for average and less skilled readers. Journal of Learning Retardation, 20(30), 271-279.

Lerner, W. (2000). Learning Retardation theories diagnosis and teaching Strategies (8th ed.). New York, Boston: Houghton Mifflin Company.

Mechling, L. C., Gast, D. L., \& Langone, J. (2002). Computer Based video instruction to teach persons with moderate Mentally Retardation to read grocery aisle signs and locate items. The Journal of Special Education, 35(4), 224-240. https://doi.org/10.1177/002246690203500404

Moussa, A. (2009). A training program in the Arabic language impact on the development of the skills of some of the linguistic expression career in children with mental disabilities who are able to learn. The Journal of the Faculty of Education. University of Assiut.

Qasim, M. A. (2000). Introduction to the psychology of language (1st ed.). Alexandria.

Ray, J., \& Warden, M. (1995). Technology, computers, and the special needs learner. Albany, NY: Delmar Publishers.

Rosan, F. (2001). Introduction to language disorders. Riyadh, Saudi: dar Zahra Publishing and Distribution.

Shehata, H. (2003). Develop oral reading skills in general education. Unpublished PhD thesis, Faculty of Education, Ain Shams University.

Sieler, W. J., \& Beall, M. M. (2005). Communication: making connections . Boston: Pearson.

Smith, M. (1988). Spoken language. In P. Schools, C. Hughes, \& M. Smith (Eds.), Community integrating for person with mental retardation (pp. 173-217). Boston, MA.: College-Hill Press. 
Taima, A. R. (2006). Atsalaa between education curricula and strategies language. Islamic Educational, Scientific and Cultural Organization.

\section{Copyrights}

Copyright for this article is retained by the author(s), with first publication rights granted to the journal.

This is an open-access article distributed under the terms and conditions of the Creative Commons Attribution license (http://creativecommons.org/licenses/by/4.0/). 